\title{
Electrochemical properties of N'-ferrocenylmethyl-N'-phenylbenzohydrazide in aqueous and organic mediums
}

\author{
Salah Neghmouche Nacer, Touhami Lanez* \\ VTRS Laboratory, Institute of Sciences and Technology, University of El-Oued, B.P.789, \\ $39000 \mathrm{El}$-Oued, Algeria
}

*E-mail address: nasersaleh78@yahoo.fr

\begin{abstract}
We carried out a detailed study of the kinetics of oxidation phenylbenzohydrazide $(\mathrm{FcX})$ to ferrocenium ion $\left(\mathrm{FcX}^{+}\right)$in aqueous and $\mathrm{gad}$. ediums. his study using cyclic $(\mathrm{CV})$ and rotating disk electrode (RDE) voltammetry s' owed that $\mathrm{FcX}_{\mathrm{A}^{+}} \mathrm{cX}^{+}$redox couple is reversible. The N'-ferrocenylmethyl-N'-phenylbenzohydr 4 and ferroco 1 ion diffusion coefficients (D) were calculated from these results. In addition, ele transfer ate constant and the exchange current density for the oxidation of ferrocene detern, A comparison of the kinetic data obtained from the two electrochemical techni ues appears to sho that the data from the RDE experiments are more reliable because they are coll ted under strict mass transport control.
\end{abstract}

Keywords: Cyclic voltammetry; diffusion coefficient; fern deriva ive; half-wave potential; Randles-Sevcik equation

\section{INTRODUCTION}

Many studies and a sis exidoreducing properties of $f$ ocene. In eral, the cathodic behavior ferrocene usual in organic media such as dich rom ane, acet sitrile and DMF can be described by a reversible reduction in an ele tron, leac to ion Ferrocerium [1-2]. In the present work the oxidation of ferrocene, $\mathrm{Fe}\left(\mathrm{C}_{5} \mathrm{H}_{5}\right)$ to the fo cenium cation, $\mathrm{Fe}\left(\mathrm{C}_{5} \mathrm{H}_{5}\right)_{2}{ }^{+}$, was examined in the solvents dichloromet e so on containing tetrabutylammonium tetrafluoroborate, and aqueous solution conta sulfuri acid using the technique of cyclic voltammetry [3-4]. The results indicat at rea reac cons of ferrocene/ ferricenium couple were a reversible process of diff sion-c htrolled agle electron transfer in both studied solutions. One of the ferrocene der ive electro, Tnsfer systems for molecular electronics owing to its characteristic redox behaviors $[5,6]$, and could also be expected to play a key role of an electron chemical probe of the electron-transferprocess in biological molecules [7,8]. It is well known that $N^{\prime}-$ Ferrocenylmethyl-N'-Phenylbenzohydrazide easily undergoes one electron oxidation to form ferrocenium cation in a reversible manner $[9,10]$ Figure 1 . Thus, we investigated the electrochemical N'-Ferrocenylmethyl-N'-Phenylbenzohydrazide behaviors in aqueous media. 


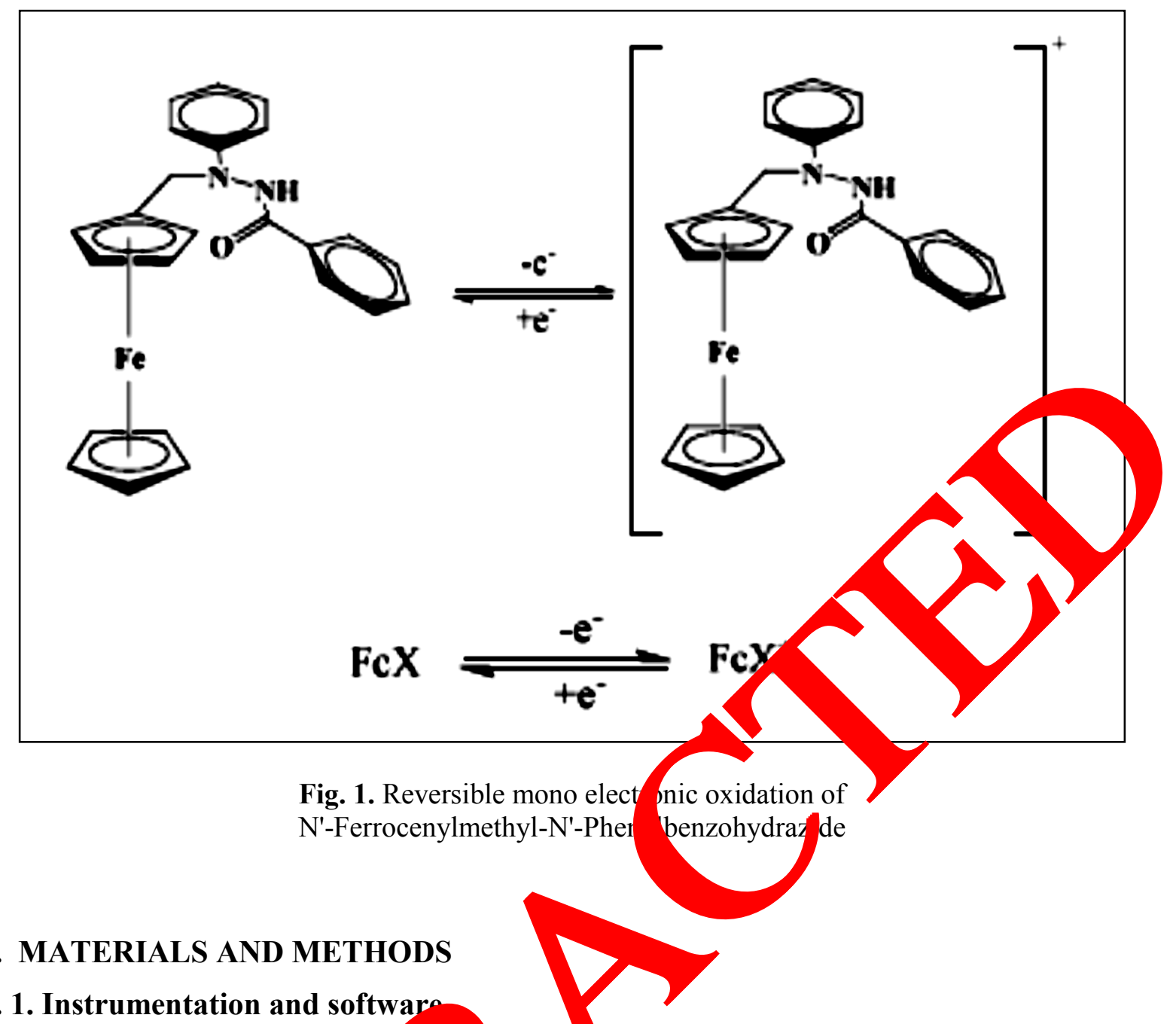

\section{1. Instrumentation and softwaro}

Cyclic voltammetric $m$ asurei ents we performed using PGZ301 potentiostat (radiometer analytical SAS a ric cell with a volumetric capacity of $25 \mathrm{ml}$ containing a glassy carbo electro GCE) working electrode (radiometer analytical SAS), a $\mathrm{Pt}$ wire counter electro a nd an $\mathrm{Hg}, \mathrm{Cl}_{2}$ reference electrode $(3.0 \mathrm{M} \mathrm{KCl})$. Solutions were deoxygenated with $\mathrm{K}$, h $\mathrm{pu}$ nitrogen for $3 \mathrm{~min}$ prior to each experiment. Data acquisitions were accomplish unith a Pe m/V (CPU 3.0 GHz and RAM $1 \mathrm{~Gb}$ ) microcomputer using VoltaMaster oftwan version .08 (radiometer analytical SAS). Graphs plot and calculus were carriea $1 \mathrm{si}$ g Urif inLab software version 2.0 (Integral Software, France).

\section{2.}

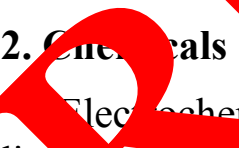

radion $r$ wor a performe deoxygenated $\mathrm{CH}_{2} \mathrm{Cl}_{2}$ and aqueous ethanol solutions of N'-Ferrocenylmethyl-N'performe rexygenated $\mathrm{CH}_{2} \mathrm{Cl}_{2}$ and aqueous ethanol solutions of $\mathrm{N}$-Ferrocenylmethyl- $\mathrm{N}$ Phenylben ohydrazide with respectively $10-1 \mathrm{M}$ of $\mathrm{Bu}_{4} \mathrm{NBF}_{4}$ and $\mathrm{H}_{2} \mathrm{SO}_{4}$ as supporting electrolyte and N'-Ferrocenylmethyl-N'-Phenylbenzohydrazide concentration of $10^{-3} \mathrm{M}$. The three electrodes used were glassy carbon disk as the working electrode, saturated calomel electrode as a reference electrode, and Pt wire as an auxiliary electrode. The working electrode was polished with $0.05 \mu \mathrm{m}$ alumina slurry for 1-2 minutes, and then rinsed with double-distilled and deionized water. This cleaning process is done before each cyclic voltammetry experiment. 


\section{RESULTS AND DISCUSSION}

\section{1. Electrochemical measurement on a fixed electrode}

The synthesized compound in previous work [5]. Cyclic voltammograms of N'Ferrocenylmethyl-N'-Phenylbenzohydrazide at glassy carbon electrode were performed at concentration of $10^{-3} \mathrm{M}$ of N'-Ferrocenylmethyl-N'-Phenylbenzohydrazide in deoxygenated dichloromethane and in aqueous ethanol solutions with respectively $10^{-1} \mathrm{M}$ of $\mathrm{Bu}_{4} \mathrm{NBF}_{4}$ and $\mathrm{H}_{2} \mathrm{SO}_{4}$ as supporting electrolyte, each solution was scanned at scan rate equal to $0.05,0.10$, 0.30 and $0.50 \mathrm{~V} \cdot \mathrm{s}^{-1}$.

The resultant CV curves and the electrochemical parameters are shown respectively in Figure 2 and Table 1.

Table 1: Electrochemical parameters obtained from voltammograms of Fig e 2.

\begin{tabular}{|c|c|c|c|c|c|c|c|c|}
\hline Mediums & $\begin{array}{c}\mathbf{v} \\
\mathrm{mV} / \mathrm{s}\end{array}$ & $\begin{array}{c}i_{p a} \\
\mu \mathrm{A} / \mathrm{cm}^{2}\end{array}$ & $\begin{array}{c}i_{p c} \\
\mu \mathrm{A} / \mathrm{cm}^{2}\end{array}$ & $\begin{array}{l}E_{p a} \\
\mathbf{m V}\end{array}$ & $E_{p c}$ & & $\overline{2}$ & . \\
\hline \multirow{4}{*}{$\begin{array}{c}\mathrm{Bu}_{4} \mathrm{NBF}_{4} \\
(\mathbf{0 . 5 g}) \\
+ \\
\mathrm{CH}_{2} \mathrm{Cl}_{2}\end{array}$} & 50 & 11.51 & -11.665 & 582.5 & & & 513.25 & 0.98 \\
\hline & 100 & 15.76 & -15.90 & 594 & & 163 & 512.5 & 0.99 \\
\hline & 300 & 25.36 & & & & 225 & 517.5 & 0.98 \\
\hline & 500 & & & & 385 & 275 & 522.5 & 0.95 \\
\hline \multirow{4}{*}{$\begin{array}{l}\mathrm{H}_{2} \mathrm{SO}_{4} \\
(\mathbf{0 . 1 M})\end{array}$} & 50 & & & 5 & 264.5 & 103 & 316 & 0.96 \\
\hline & & & & 372 & 258 & 114 & 315 & 0.99 \\
\hline & & & -33.58 & 381 & 258 & 123 & 319.5 & 0.94 \\
\hline & & 40.4 & -42.52 & 395 & 250 & 145 & 322.5 & 0.95 \\
\hline
\end{tabular}

The dic and the cathodic peak heights as function of the square root of the scanning rate for glassy carbon electrode in different medium are shown in Figure 3. The obtained linear relation ship indicates clear diffusion character.

As it can be seen from figures 3, the ratio of the anodic and cathodic current peak heights is close to one for both solutions; this indicates the reversible character of the oxidation of N'-Ferrocenylmethyl-N'-Phenylbenzohydrazide in both studied medium. 

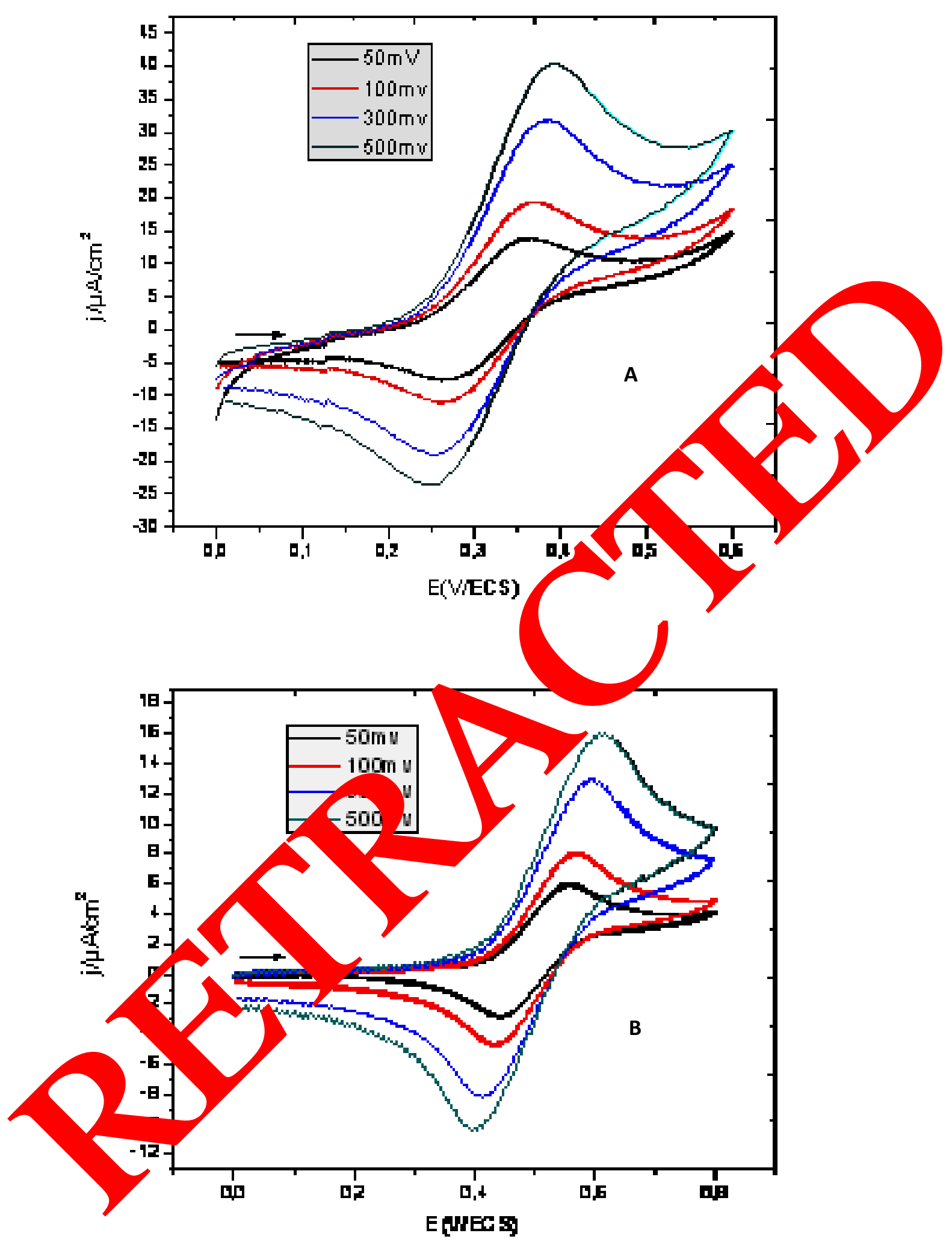

Fig. 2 (A, B). cyclic voltammetry of $1 \mathrm{mM}$ N'-Ferrocenylmethyl-N'-Phenylbenzohydrazide in (B) $100 \mathrm{mM} \mathrm{Bu}_{4} \mathrm{NBF}_{4}$ in $\mathrm{CH}_{2} \mathrm{Cl}_{2}$ and (A) in ethanol/aq. $\mathrm{H}_{2} \mathrm{SO}_{4}$ at $2 \mathrm{~mm}$ diameter glassy carbon working electrode, Pt counter electrode, and CSE reference electrode at $\left(0.05,0.10,0.30,0.50 \mathrm{~V} . \mathrm{s}^{-1}\right)$. 


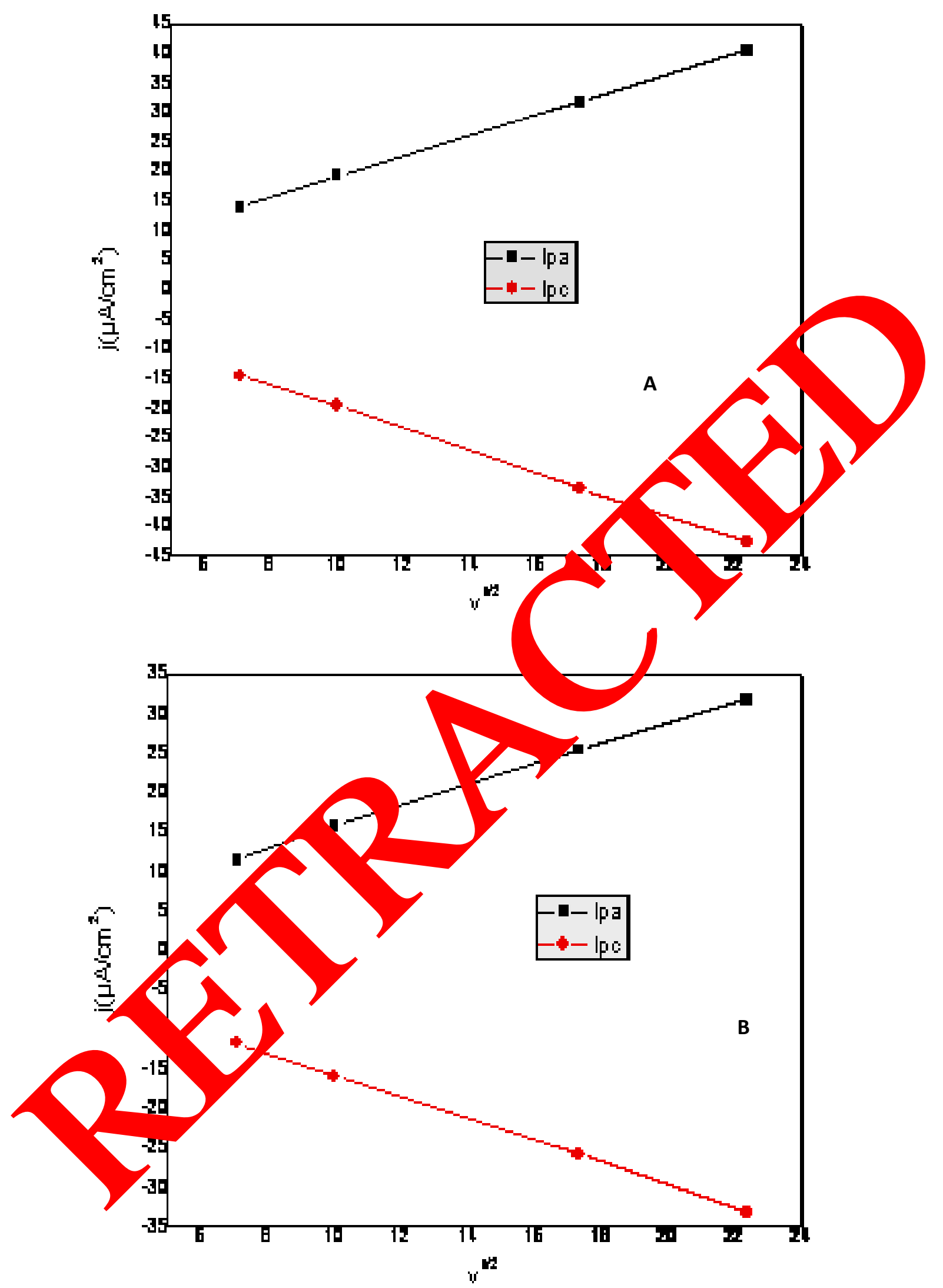

Fig. 3. The anodic and the cathodic peak heights as function of the square root of the scanning rate in $\mathrm{CH}_{2} \mathrm{Cl}_{2}(\mathrm{~B})$ and in ethanol/ $\mathrm{H}_{2} \mathrm{SO}_{4}(\mathrm{~A})$ at $2 \mathrm{~mm}$ diameter glassy carbon working electrode 


\section{2. Electrochemical measurement on rotating disk electrode}

Rotating disk electrode is a hydrodynamic electrode technique which utilizes convection as the mode of mass transport as opposed to $\mathrm{CV}$ which is governed by diffusion. Convection is more efficient and is not diffusion limited with the result that the analytical data is more reproducible and precise.

Thus a comparison of the kinetic parameters obtained from CV and RDE experiments is informative to elucidate the role of mass transport on electrode reaction kinetics. Figure $4 \mathrm{~A}$ shows RDE voltammograms for N'-Ferrocenylmethyl-N'-Phenylbenzohydrazide at a series of rotation rates.

It is evident from the data that the current generated by the RDE method is much larger than that generated under diffusion control.

The much larger current obtained using RDE reflects the efficiency of this nethod. notice that there is significant increase in anodic current while the amount of ca dic curre is negligible, essentially making the cyclic voltammogram anodic. This is to th ast

The diffusion current limit, the current half-wave and half-wave otentiv are calded at different rotation speed of the electrode, Table 2.

Table 2. Electrochemical parameters calculated from polar nes obtain glassy carbon electrode of different rotational speed ii wo m

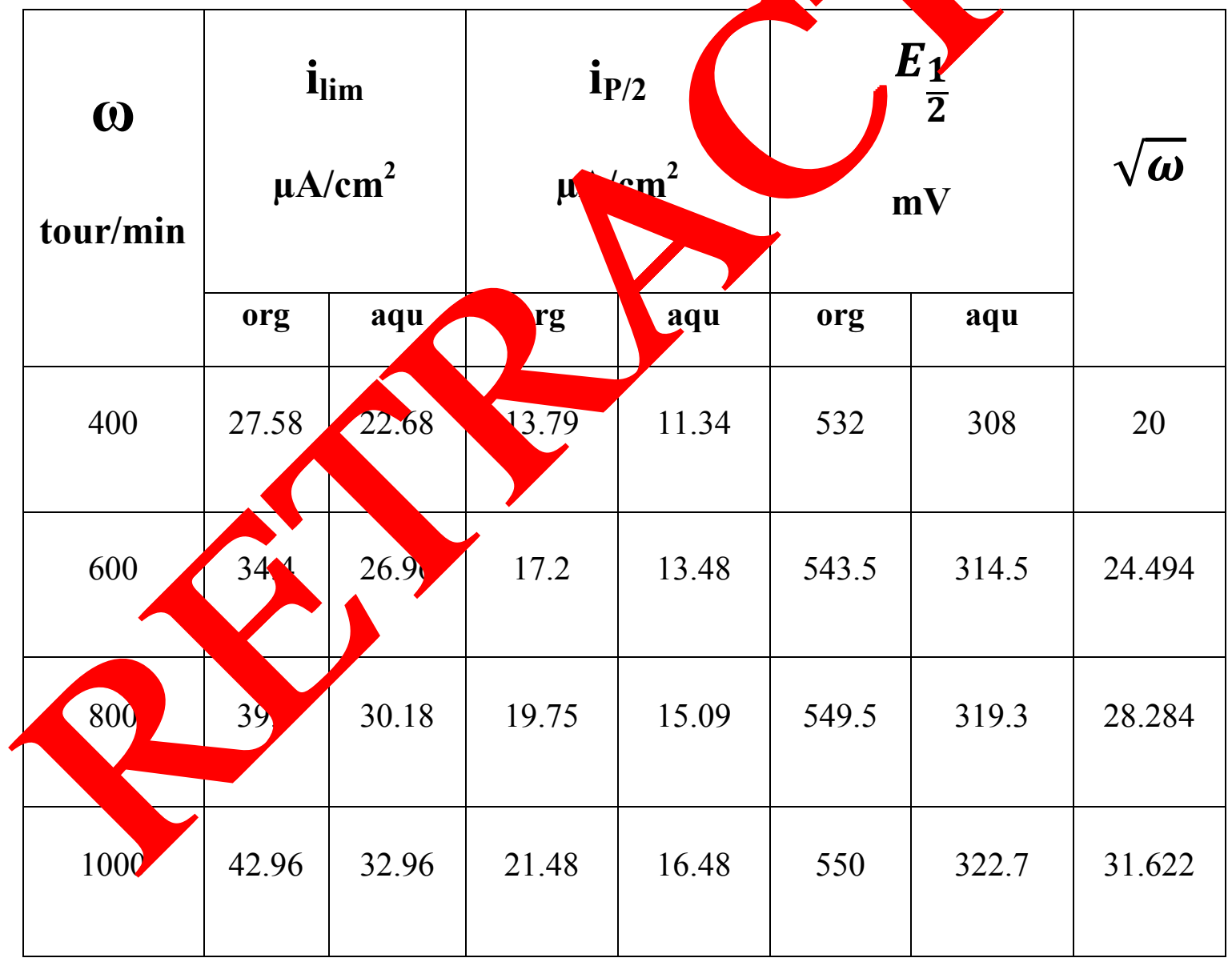



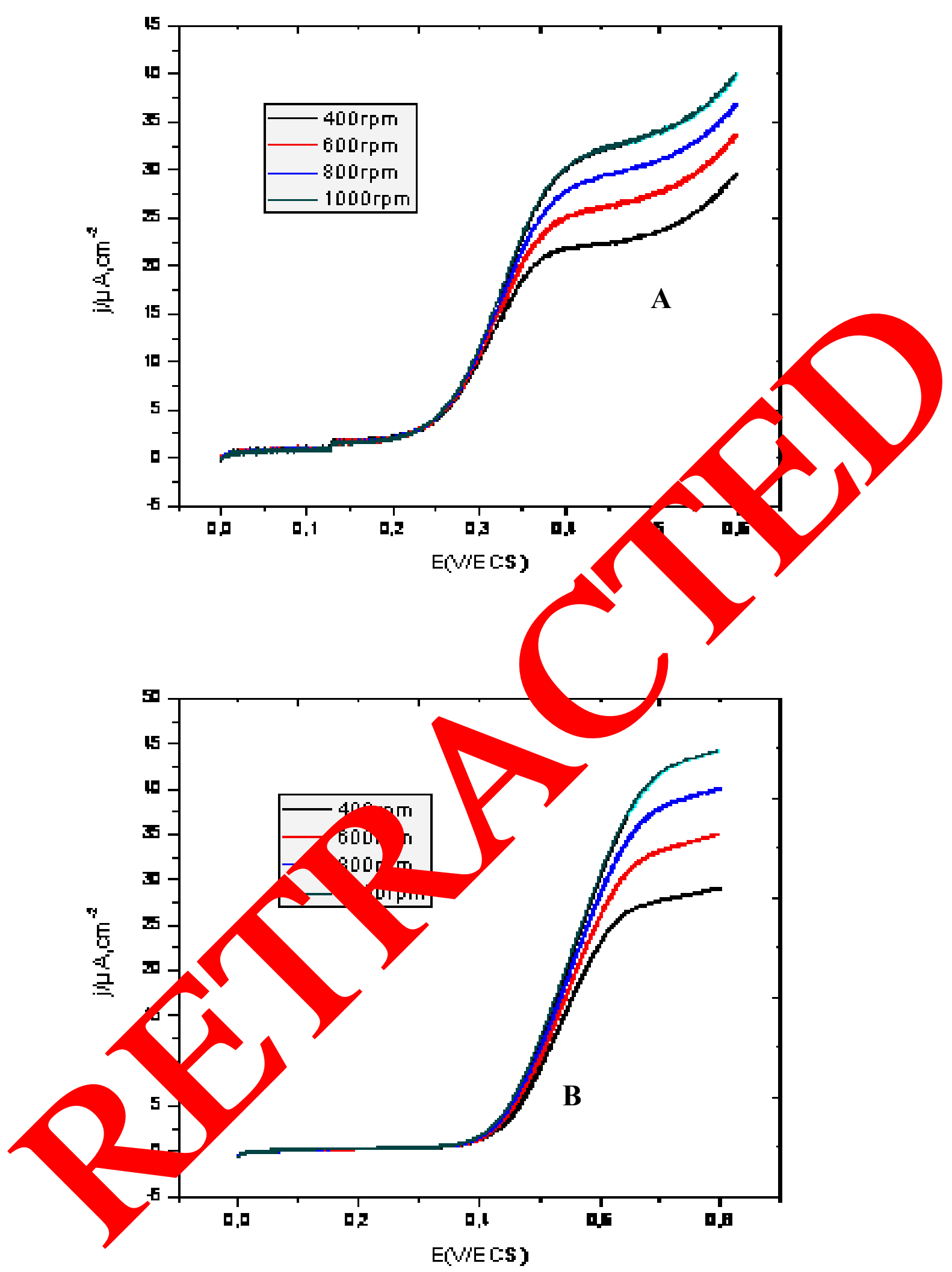

Fig. 4(A, B). Polarogramme of (B) $1 \mathrm{mM} \mathrm{N}$ '-Ferrocenylmethyl-N'-Phenylbenzohydrazide and $100 \mathrm{mM} \mathrm{Bu}_{4} \mathrm{NBF}_{4}$ in $\mathrm{CH}_{2} \mathrm{Cl}_{2}$ and (A) $1 \mathrm{mM}$ of N'-Ferrocenylmethyl-N'-Phenylbenzohydrazide in ethanol/ $\mathrm{H}_{2} \mathrm{SO}_{4}$ at $2 \mathrm{~mm}$ diameter glassy carbon working electrode, $\mathrm{Pt}$ counter electrode, and CSE reference electrode at $0.50 \mathrm{~V} \cdot \mathrm{s}^{-1}$. (Rotating rate $400,600,800,1000 \mathrm{rpm}$ ). 


\section{3. Calculation of diffusion coefficient}

The Levich equation predicts the current observed at a rotating disk electrode and shows that the current is proportional to the square root of rotation speed. The equation is:

$$
\delta=0.645 D_{O x}^{\frac{1}{3}} \gamma^{\frac{1}{2}} \omega^{-\frac{1}{2}}
$$

Where $\mathrm{D}_{\mathrm{ox}}$ : diffusion coefficient of the oxidant is expressed in $\mathrm{cm}^{2} . \mathrm{s}^{-1}$

$\omega$ : rotational speed of the electrode $\left(\mathrm{rad} \mathrm{s}^{-1}\right)$

$\gamma$ : kinematic viscosity in $\mathrm{cm}^{2} . \mathrm{s}^{-1}$

Kinematic viscosity: is the ratio of the viscosity on the density, we have for dichl cometh vi

$$
\begin{gathered}
\text { viscosity }=0.43 \mathrm{mPa} \cdot \mathrm{s} \quad 25^{\circ} \mathrm{C} \\
\text { density } \mathrm{d}=1.328
\end{gathered}
$$

$\gamma=\frac{0.43}{1.328} \times 10^{-3} \frac{\frac{\mathrm{kg}}{\mathrm{m} \cdot \mathrm{s}}}{\frac{\mathrm{kg}}{\mathrm{m}^{3}}}=0.323 \times 10^{-3} \frac{\mathrm{m}^{3}}{\mathrm{~m} \cdot \mathrm{s}}=0 \mathrm{~s} \times 10^{-3} \cdot \mathrm{j}^{4} \mathrm{~cm}^{2} \cdot \mathrm{s}^{-1}$

$$
=0.0323 \mathrm{~cm}^{2} \cdot \mathrm{s}^{-1}
$$

$\gamma=0.0323 \mathrm{~cm}^{2} \cdot \mathrm{s}^{-1}$

The kinematic viscosity $\left(\approx 10^{-6} \mathrm{~m}^{2} \cdot \mathrm{s}^{-1}\right.$, for an a vous solution at $\left.25^{\circ} \mathrm{C}\right)$

The relationship between $\mathrm{i}$ and the root rotation speed

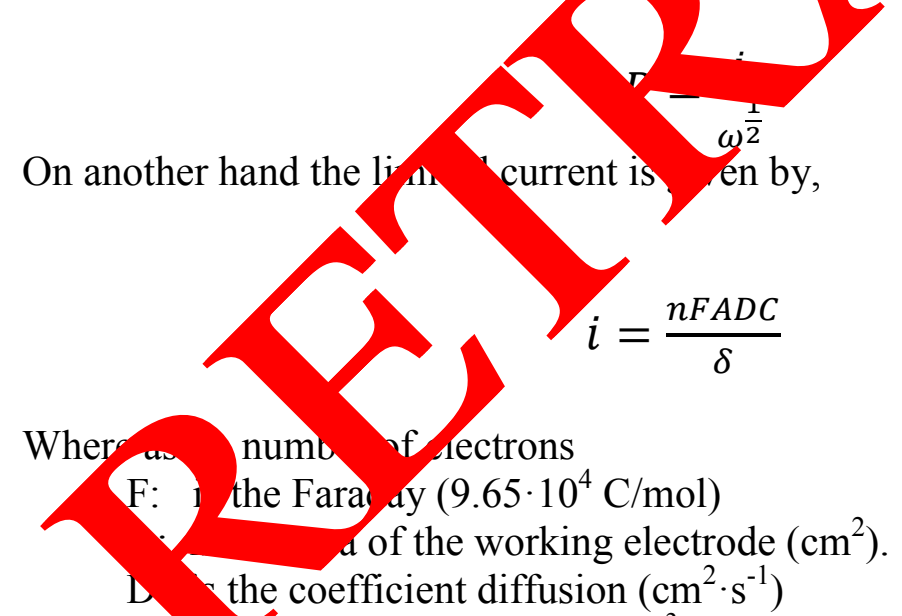

C: $1 \mathrm{e}$ concentration $\left(\mathrm{mol} / \mathrm{cm}^{3}\right)$, in our case is equal to $10^{-3} \mathrm{~mol} / 1$

Replacing equations 2 and 3 in 4 gives,

$$
D^{\frac{2}{3}}=\frac{P 1.61 \gamma^{\frac{1}{6}}}{n F A C \sqrt{2 \pi}}
$$


For a rotating rate of the working electrode equal to $400 \mathrm{t} / \mathrm{min}$., the coefficient diffusion of N'-Ferrocenylmethyl-N'-Phenylbenzohydrazide in dichlormethane is.

$$
D=13.2 \times 10^{-6} \mathrm{~cm}^{2} \cdot \mathrm{s}^{-1}
$$

The coefficient diffusion of ferrocene in aqueous ethanol is calculated as above. Table 2 summarize the obtained values.

Table 3. Diffusion coefficients of compoud calculated from polarogramme of Figure 5.

\begin{tabular}{|c|c|c|c|}
\hline Electrode/medium & $\boldsymbol{p}$ & $\boldsymbol{D} \times \mathbf{1 0}^{-\mathbf{6}} \mathbf{c m}^{\mathbf{2}} \mathbf{s}$ & $\boldsymbol{\delta}(\mathbf{n m})$ \\
\hline $\mathrm{GC} / \mathrm{CH}_{2} \mathrm{Cl}_{2}$ & 1.4 & 13.2 \\
\hline $\mathrm{GC} /$ aq.ethanol & 1.1 & 2.6 \\
\hline
\end{tabular}

\section{CONCLUSION}

Voltammetry analysis on a fixed e 'ode of N'-Ferrocenylmethyl-N'Phenylbenzohydrazide in aqueous and org solutions mdicates that the electrochemical reaction of N'-Ferrocenylmethyl-N'-Phenyl snzo somide in both studied solutions is a diffusion controlled process, namely, electr bmica process and,show that the electron withdrawing N'-Phenylbenzohydr group il roduced to the ferrocene influences the redox potential of the iron centre. $T$ is is ay be $d /$ to the non-insulating effect of methylene between the N'-Phenylbenz ay the cyclopentadienyl ring of ferrocene. In addition $\Delta \mathrm{Ep}$ for the ferr cene in $\mathrm{Q} \mathrm{Cl}_{2}$ is grater than $\Delta \mathrm{Ep}$ in aq. ethanol, this difference can be attributed to the dis nce in din coefficient between ferrocene in each medium which is a major co tribu. However there is a minor contributor which is related to the difference in the orution resis sof the two electrochemical medium.

\section{References}

Th authors g atefully acknowledge Mr A. Khelef Maitre assistant at The University of El Oued advice, and the Technical staff in the laboratory of VPRS for its support.

[1] Gritzner G., Pure Appl. Chem. 56 (1984) 461.

[2] Page J. A., Wilkinson G., J. Am. Chem. Soc. 74 (1952) 6149-6150.

[3] Kealy T. J., Pauson P. L., Nature 168 (1951) 1039-1040. 
[4] Khelef A., Neghmouche N. S., Lanez T., Rev. Sci. Fond. App. 3(2) (2011) 75-84.

[5] Terki B., Lanez T., Belaidi S., Gornitzka H., Asian J. Chem. 18(3) (2006) 2074-2080.

[6] Bath B. D., Scott E. R., Phipps J. B., White H. S., J. Pharm. Sci. 89(12) (2000) 1537-1549.

[7] Osgerby J. M., Pauson P. L., J. Chem. Soc. (1958) 642.

[8] Perrin D. D., Armarego W. L. F., Purification of laboratory Chemicals, Pergamon Press, New York 1988.

[9] Neghmouche N. S., Khelef A., Lanez T., Rev. Sci. Fond. App. 1(1), (2009) 23-30.

[10] Neghmouche N. S., Khelef A., Lanez T., RJPBCS 1(1), (2010) 76-82.

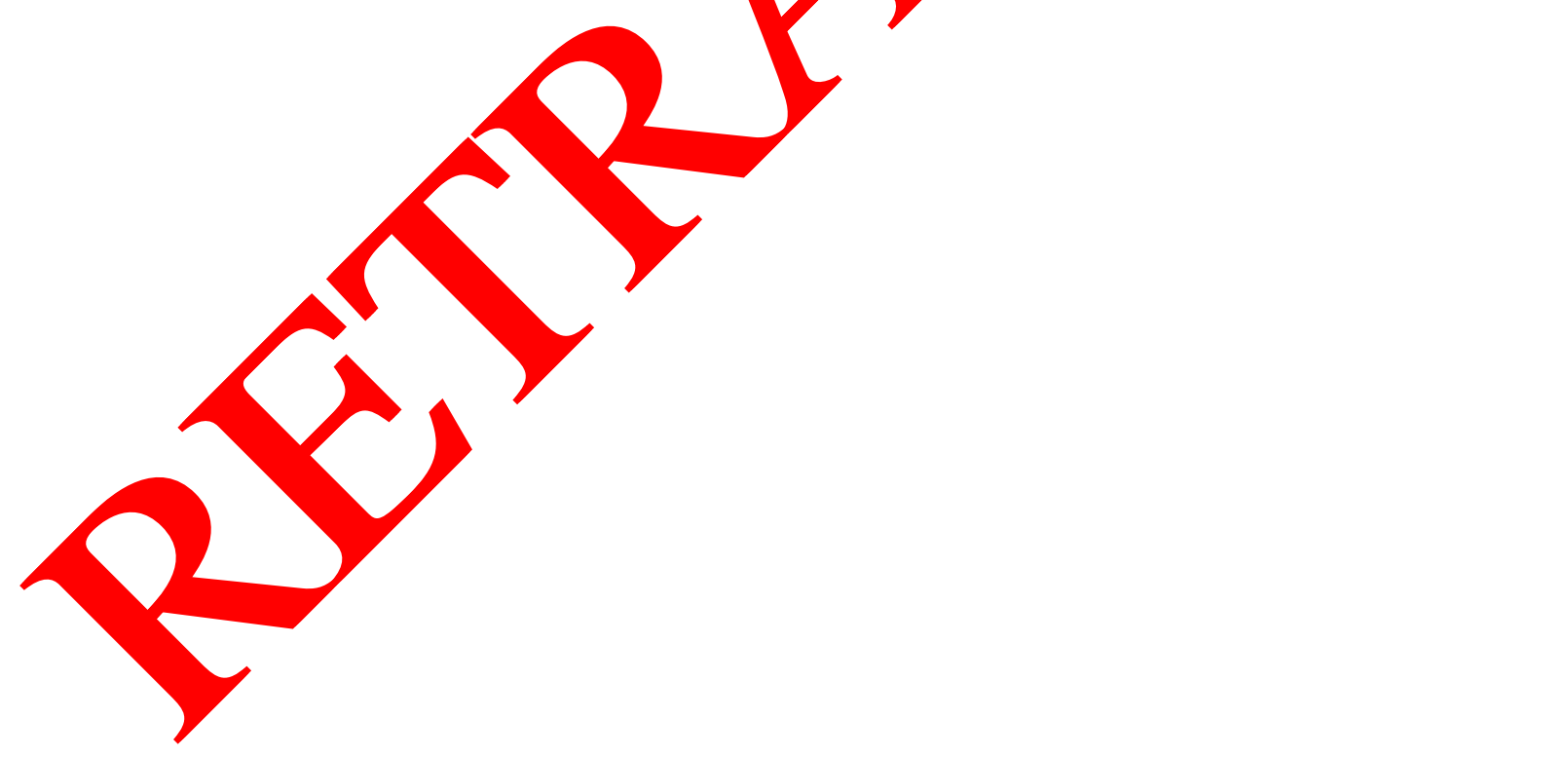

